\title{
Business Ethics - Academic discourse or good business?
}

A major challenge for those seeking to enhance the credibility and acceptability of the discipline amongst practicing managers and business people is that of relevance and applicability. As long as business ethics is seen to be the province of academics, philosophers and theologians, it will struggle to gain acceptance as a meaningful dimension of organisational behaviour, from the perspective of the business community. Additionally, the normative emphasis of the debate on business ethics which often implies that being ethical and being profitable are somehow alternatives rather than compatible objectives further minimises the credibility of the subject for practicing managers. Yet, it is possible to present a win-win argument to managers, i.e. that being ethical can also be profitable to the enterprise.

How might this be done? The notion of enlightened self-interest can be explored as a means of enhancing the perceived relevance of business ethics to the practice of management. Several interesting dimensions of this debate relate to the notions of governance and trust in organisations.

Delayering has reduced the levels of management in organisations, and technology has disseminated information for decision-making to much lower levels in the organisation, thus minimising the traditional control mechanisms exerted in organisations over employee behaviour. Thus, the responsibility of employees to manage themselves and take greater responsibility for their role in the organisation has been greatly enhanced.

This trend has been further re-enforced by the strategies of empowerment and reward management which focus upon individual contribution to the enterprise. These changes have led to greater self-governance and self-regulation on the part of employees in terms of their behaviour in the enterprise. Consequently, organisations are required to trust employees to act in ways that are supportive of the strategy of the enterprise, if they are to maximise the effectiveness of employees within the organisation.

Effective trust implies reciprocity and transparency in the conduct of those parties involved in the transaction, as, once a trust is broken, it is difficult for the relationship to continue in the longer term in a way that it optimises the outcomes to the benefit of both parties. Indeed, this notion of trust and transparency can be extended to cover the relationship between all stakeholders in an enterprise, thus encouraging enterprises to extend their responsibility to all stakeholders and not simply shareholders. This will also enhance the long term perspective of organisations and lessen the short-termism, with its adverse effects on the functioning of enterprises.

To the extent that business ethics is concerned with the conduct of human behaviour in organisations it is to be expected that the human resource 
management function would have a significant role to play in the promotion of ethical behaviour within organisations. A primary aspect of the human resource management function in this context relates to the role of education and training which had a major role to play in changing attitudes and behaviour. At its most successful, such policies become integral to the strategy and culture of the enterprise so that it becomes a 'learning organisation'. Within this context the willingness of employees to constantly learn and develop will help to promote an openness of attitude and thinking which recognises that behaviour and business can be both ethical and profitable.

What happens then when we take the complex debate on ethics in general and business ethics in particular, and set in the context of Central and Eastern Europe? It has been the experience of the writer that two responses frequently emerge. The first response claims that Central and Eastern Europe are different from the rest of the Western world in terms of the problems that they face. I believe this to be invalid recourse to moral relativism. On the basis of being 'different' it is argued that in certain circumstances basic moral rights and responsibilities do not apply. The problems in Central and Eastern Europe may be of greater magnitude than similar experiences in Western countries and indeed may have some of their root causes embedded in the past regimes. In essence, however, they are not qualitatively different from the moral dilemmas and debates which occur in other countries.

The second response is also interesting. Those who seek to put forward solutions to some of the ethical problems of the region, frequently refer to the integral role of the state and regulation in this process. What has been interesting is the absence of serious discourse on the responsibilities of the civil society in this process. It is the belief of the author that until this debate on the development of a meaningful civil society is effectively engaged, then many of the root causes of the ethical problems facing the region will remain unresolved and grow in magnitude.

Perhaps the critical distinction between the countries of the West and those of Central and Eastern Europe relates to the degree to which unethical practices are institutionally

embedded within the system. When the point is reached whereby citizens rights and expectations are distorted to the extent that they are seen as discretionary, and corrupt business practices are the institutional norm, then the legitimate development of the civil society and the progress of democracy itself could be adversely distorted.

Anne Mills, Buckinghamshire Chilterns University College 